\title{
Simultaneous Open Reduction and Salter Innominate Osteotomy for Developmental Dysplasia of the Hip
}

\author{
G.K. Museve, MBChB, MMed (Surg), Department of Orthopaedic Surgery, College of Health Sciences, \\ University of Nairobi, P.O. Box 29829-00200, Nairobi, Kenya \\ Email:gkmuseve@yahoo.co.uk
}

\begin{abstract}
Objective: To highlight the presence of this uncommon developmental disorder in our set up and show that simultaneous open reduction and salter innominate osteotomy can restore normal hip development

Design: Prospective study.

Setting: Kenyatta National Hospital between 2002 and 2004.

Subjects: Children with typical developmental dysplasia of the hip (DDH) who were 18 months and above were operated on.

Methods: Clinical and radiological assessment of the hips was done and skin traction was applied for between two to four weeks until femoral head came down to the level of the acetabulum. Open reduction, iliopsoas and adductor releases, capsulorraphy and salter innominate osteotomy was then done. The graft was held by two smooth Kirschner (k) wires. Unlike Salter, the femoral head was held in the socket by a smooth Kwire. A hip spica was applied for 12 weeks and thereafter the children were allowed to mobilize freely at their own pace. Follow up clinical and radiological assessment was done.

Results: Two female children with three congenital dislocations of the hips were operated. They were 18 months and three and a half years old at the time of the initial surgery. At follow up of between nine and 27 months, there was good initial clinical and radiological outcome. The average acetabular index dropped from an average of 41 degrees pre-operatively to an average of 18 degrees post-operatively.

Conclusion: This operation redirects the acetabulum without deepening it, achieving good femoral head coverage. Long term follow is intended. Pooling of patients with this uncommon disorder in our environment is advocated to further develop surgical competency. Early competent screening of new born babies could enable early conservative management with good outcome.
\end{abstract}

\section{INTRODUCTION}

Typical developmental dysplasia of the hip comprises a wide spectrum of abnormalities ranging from simple hip instability with capsular laxity to complete displacement of the femoral head out of an anomalous acetabular socket. With restoration of normal articular relations between the femoral head and acetabulum, the anatomical changes are reversible in time with growth $(1,2)$.

It is claimed that adequate acetabular remodeling is possible only during the first 18 months of life. After this, satisfactory development cannot always be assured by non-operative treatment following closed reduction. For this group of patients over the age of 18 months as well as for those in whom earlier non-operative treatment has failed to produce a satisfactory joint, Salter innominate osteotomy has proved to be most useful (2).

Salter, in 1961, introduced the innominate osteotomy for the treatment of acetabular dysplasia associated with congenital dislocation and subluxation of the hip. Clinical observations in children and experimental observations in animals led Salter to believe that in the older child (over 18 months), the most significant aspect of acetabular dysplasia is an abnormal direction in which the acetabulum faces (acetabular maldirection): instead of facing downward, it faces more anteriorly and laterally than normal. $\mathrm{He}$ reasoned that re-orienting the maldirected acetabulum would render the reduced hip more stable and would increase the load-bearing area of the acetabulum in the 
weight bearing position while not altering the shape or volume (3).

Salter and Dubois (2) gave the following as indications for the innominate osteotomy:- congenital dislocation or residual redislocation at the ages of one and a half years to six years or congenital subluxation or residual resubluxation at the ages of one and a half years to adult life.

The prerequisites are:- ability to bring the head of femur opposite the acetubulum, release of contractures of the adductors and iliopsoas, complete and concentric reduction of the femoral head in the depth of the true acetabulum, reasonable congruity of the hip, a good range of hip motion and the correct age of the patient.

They achieved $100 \%$ excellent clinical results in all cases and $93.6 \%$ excellent or good radiological results based on Severin classification in all 110 hips which underwent primary simultaneous open reduction and innominate osteotomy in children who were operated between the ages of one and a half years to four years. In those cases who were above four years to ten years, the excellent and good radiological results were only $56.7 \%$.

\section{MATERIALS AND METHODS}

This was a prospective study in which children with typical DDH who were 18 months and above were operated at the Kenyatta National Hospital between 2002 and 2004. Clinical assessment included presence or absence of pain, limb length, range of hip motions and gait, both pre and post-operatively and reducability pre-operatively. Radiological assessment included a pelvic anteroposterior view in which the dislocation was confirmed and measurement of the acetabular index was done. An additional lateral view was done postoperatively. Pre-operative skin traction was applied for between two to four weeks until the femoral head came down to the level of acetabulum. Open reduction, iliopsoas and adductor releases, capsulorraphy and Salter innominate osteotomy was then done. The graft was then held by two smooth kirschner $(k)$ wires. Unlike Salter, the femoral head was held in the socket by a smooth k-wire. A hip spica was applied for 12 weeks and there after the children were allowed to mobilize freely on their own pace.

\section{RESULTS}

Two female children with irreducible three DDH were operated. They were one and a half years and three and a half years at the time of the initial surgery. Follow up was between nine and 27 months at the ages of three and a half years and four years nine months respectively. All the three hips had normal range of painless hip motion with normal gait. In the unilateral case, the limb was longer by $0.5 \mathrm{~cm}$.

Table 1

Acetabular indices

\begin{tabular}{lcc}
\hline Hip & $\begin{array}{c}\text { Pre-operative } \\
\text { (degrees) }\end{array}$ & $\begin{array}{c}\text { Post-operative } \\
\text { (degrees) }\end{array}$ \\
\hline 1 (Left) & 40 & 8 \\
2 (Right) & 50 & 22 \\
3 (Left) & 33 & 24 \\
Average & 41 & 18 \\
\hline
\end{tabular}

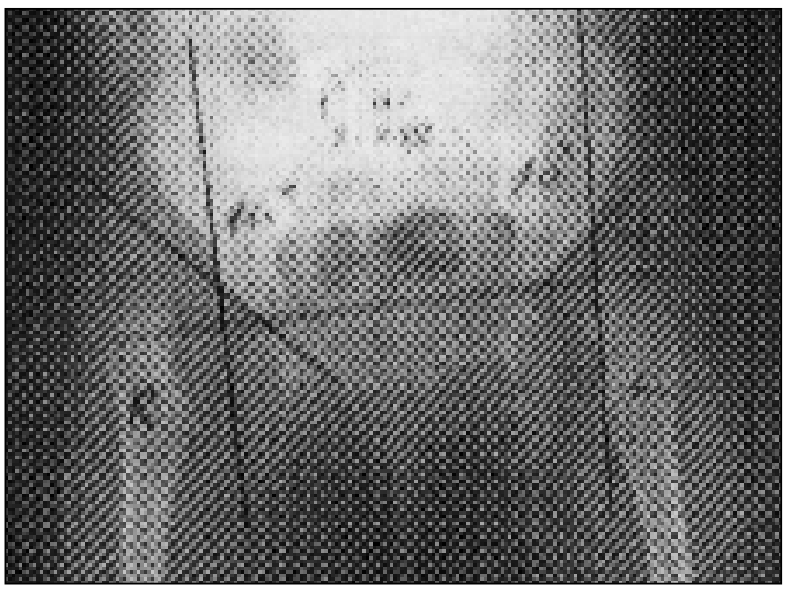

Figure 1: Case 1 - Pre-operatively (Skin traction on the left limb)

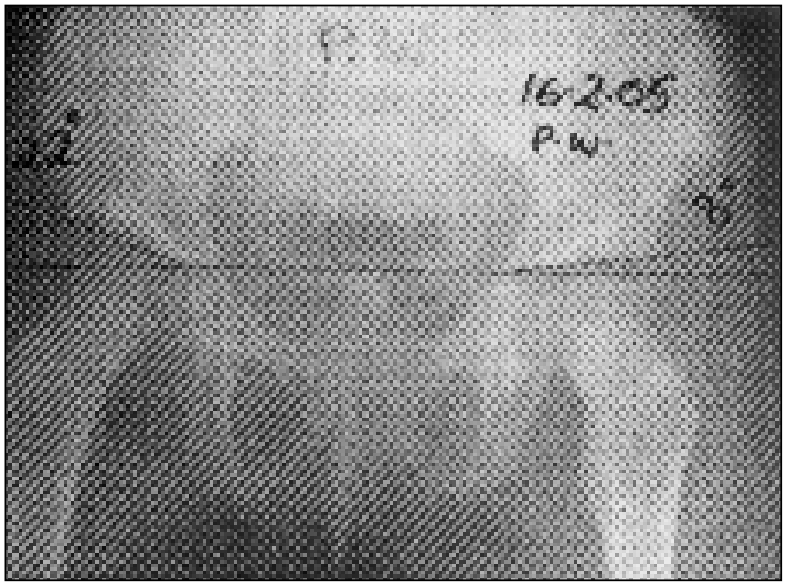

Figure 2: Case 1 - Post-operatively 


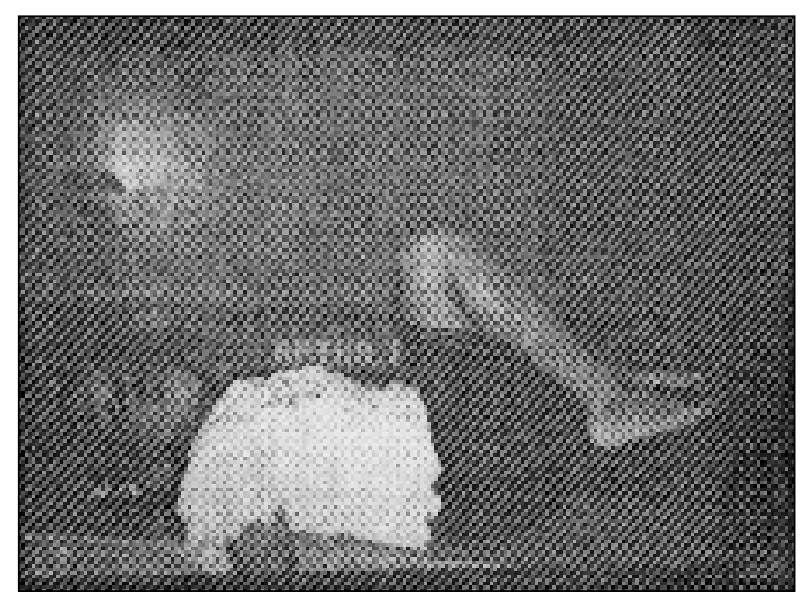

Figure 3: Case 1 - Post-operative

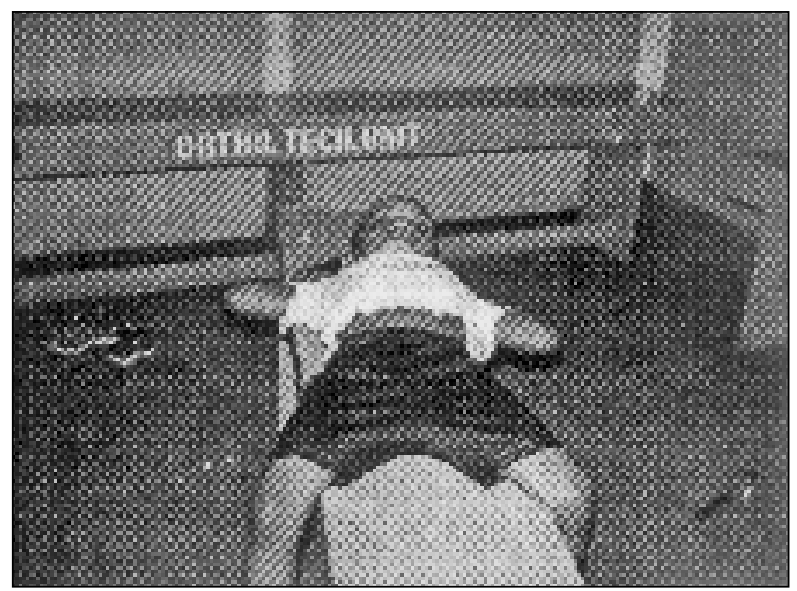

Figure 4: Case 1 - Post-operative

\section{DISCUSSION}

Through clinical observations in children and experimental observations in animals led Salter to believe that re-orienting the maldirected acetabulum in the older child (over 18 months) rendered the reduced hip more stable and increased the femoral head coverage there by increasing the load bearing area of the acetabulum in the weight bearing position while not altering the shape or volume (3).

Salter and Dubois (2) achieved 100\% excellent clinical results in all cases and $93.6 \%$ excellent or good radiological results based on Severin classification in all 110 hips which underwent primary simultaneous open reduction and innominate osteotomy in children who were operated between the ages of one and a half years to four years. In those cases who were above four years to ten years, the excellent and good radiological results were only $56.7 \%$.
Evans et al (4) achieved 97.3\% excellent or good clinical results according to Mckay classification and $83.8 \%$ excellent or good radiological results based on Severins criteria. Mckay (5) did not achieve similar results to Salter and Dubos (2) due to failure to adhere to specific guidelines for the procedure as well as technical difficulties.

While Barrett et al did not achieve similar results, they concurred with Salter and Dubos that patients who had an open reduction combined with innominate osteotomy before the age of four years had better results and required fewer subsequent procedures than did patients who had the operation after the age of four years (6).

In the current study, a full range of painless hip motion and normal gaite was achieved in the three hips. There was good radiological coverage of the femoral heads. Harris, while assessing acetabular growth potential concluded that if congruity is obtained under four years of age, growth of acetabulum will continue resulting in a normal or mildly dysplastic acetabulum (7). Barret et al (6) achieved an average of acetabulum index of 18 degrees at follow up from average of 34 degrees pre-operatively while Bohm and Brzuske (8) had 20.1 degrees from an average of 32 degrees preoperatively. In this study a good average acetabular index of 18 degrees was achieved from a preoperative average of 41 degrees.

Bohm and Bruzuske in their long term follow-up had $20.5 \%$ of the 73 hips considered a failure, which was defined as a revision or a Harris score of less than 70 points. With true revision as the end point the cummulative survival rate at 35.3 years was 0.9 . They found out that patients managed by open reduction and innominate osteotomy had better results than open reduction alone and that avascular necrosis was associated with high risk of osteoarthritis (8).

There are complications associated with open reduction and innominate osteotomy. The incidence of a vascular necrosis vary considerably, ranging from $5.7 \%$ from simultaneous open reduction and innominate ostetomy (Salter and Dubos (2) to $37 \%$ after open reduction alone (Thomas et al 1989) (9). Barrett et al had 6\% (6).

Haidar et al had the following complications:Avascular necrosis $8.1 \%$, secondary subluxation $5.4 \%$ superficial infection $8.1 \%$ significant leg-length descrepancy $2.7 \%$ supracondylar femoral fracture $5.4 \%$ (4). Mckay had a redislocation rate of $11 \%$ due to technical failures (5). Other authors had no dislocations $(2,4)$. 


\section{CONCLUSIONS AND RECOMMENDATIONS}

The current study showed good initial clinical and radiological results. Long term follow-up is necessary. The study therefore supports the use of combined open reduction and Salter innominate osteotomy at 18 months to four years. We however are limited by the few number of these cases at Kenyatta National Hospital, as they are uncommon. Pooling of patients with this uncommon disorder in our environment is advocated to further develop surgical competency. Early competent screening of new born babies could enable conservative management with good outcome.

\section{RERERENCES}

1. Tachdjan M.O. Paediatric orthopaedics Vol I. Second edition pg 298, 1990 W.B Saunders Company.

2. Salter R.B. and Dubois, Jean-Pierre. The first fifteen years' personal experience with innominate osteotomy in the treatment of congenital dislocation and subluxation of the hip. Clin. Orthop. Res. 1974; 98: 72-103.

3. Salter R.B. Innominate osteotomy in the treatment of congenital dislocation and subluxation of the hip. J. Bone Joint Surg. 1961; 43-B(3): 518-539.

4. Haidar R.K., Jones R.S., Vergroesen D.A. and Evans G.A. Simultaneous open reduction and Salter innominate osteotomy for developmental dysplasia of the hip. J. Bone Joint Surg. 1996; 78-B(3): 471-476.

5. Mckay D.W. A comparison of the innominate and pericapsular osteotomy in the treatment of congenital dislocation of the hip. Clin. Orthop. Res. 1974; 98: 124-132.

6. Barrett W.P., Staheli L.T. and Chew D.E. The effectiveness of the Salter innominate osteotomy in the treatment of congenital dislocation of the hip. J. Bone Joint Surg. 1986; 68-A: 79-87.

7. Harris N.H. Acetabular growth potential in congenital dislocation of the hip and some factors upon which it may depend. Clin. Orthop. Res. 1976; 119: 99-106.

8. Bohm P. and Brzuske A.M. Salter innominate osteotomy for the treatment of developmental dysplasia of the hip in children. J. Bone Joint Surg. 2002; 84-A: 178-186.

9. Thomas H., Dunin A.J., Cole W.G. and Menelaus M.B. Avascular necrosis after open reduction of congenital dislocation of the hip: Analysis of causative factors and natural history. J. Paediat. Othorp. 1998; 9: 525-531. 